\title{
Higiene, tipologia da infância e institucionalização da criança pobre no Brasil (1875-1899)
}

\author{
IRMA RIZZINI \\ Universidade Federal do Rio de \\ Janeiro, Rio de Janeiro, RJ, Brasil \\ JOSÉ GONÇALVES GONDRA \\ Universidade do Estado do Rio de \\ Janeiro, Rio de Janeiro, RJ, Brasil
}

RESUMO

Neste estudo investigamos a emergência da infância como problema social e o tratamento dado ao tema pelos médicos higienistas formados na Faculdade de Medicina do Rio de Janeiro, lugar que proporcionava largo diálogo com a produção dos países considerados modelo de civilização. Ao mesmo tempo, procuramos analisar as marcas dos discursos higienistas em dois internatos criados entre 1875 e 1899 no Rio de Janeiro, voltados para crianças classificadas na literatura especializada e na documentação das instituições de recolhimento como órfãs, abandonadas e desvalidas. Trabalhando com discursos produtores de saberes dirigidos à gestão das infâncias, constituímos como fontes os meios de difusão desses elementos, como teses, livros e periódicos especializados, mas também os documentos das instituições que informam sobre seus projetos de reforma e descrevem práticas cotidianas, como regulamentos e relatórios.

\section{PALAVRAS-CHAVE}

higiene; infância; internatos; Rio de Janeiro (1875-1899). 


\section{HYGIENE, CHILDHOOD TYPOLOGYS AND INSTITUTIONALIZATION OF POOR CHILDREN IN BRAZIL (1875-1899)}

\section{ABSTRACT}

This study investigated the emergence of childhood as a social problem and how the subject was treated by hygienists, whom were graduates from the Medical School of Rio de Janeiro. This institution allowed broad dialogue with countries regarded as paradigms of civilization with regard to dissertations on the subject. At the same time, we attempted to analyze the imprints left by these hygienists' discourses on two institutions created between 1875 and 1899 in Rio de Janeiro, focused on children who were classified as orphans, abandoned, and destitute in the specialized literature and records of detention facilities. Working with knowledge-producing discourses focused on the management of these children in order to disseminate the mentioned discourses, our sources were constituted of theses, books and specialized journals, as well as documents from the boarding schools, which recorded their reform projects and described their daily and operational practices, such as regulations and reports.

\section{KEYWORDS}

hygiene; childhood; boarding schools; Rio de Janeiro (1875-1899).

\section{HIGIENE, TIPOLOGÍAS DE LA INFANCIA Y LA INSTITUCIONALIZACIÓN DE LOS NIÑOS POBRES DE BRASIL (1875-1899)}

\section{RESUMEN}

En este estudio, investigamos la aparición de la infancia como un problema social y el tratamiento dado al tema por los médicos-higienistas, graduados en la Facultad de Medicina de Río de Janeiro, un sitio que ofrece amplio diálogo con la producción de los países considerados como un modelo de civilización. Al mismo tiempo, analizamos las marcas de los discursos higienistas en dos internados construidos entre 1875 y 1899 en Río de Janeiro, dirigidos a los niños, clasificados en la literatura y en la documentación de las instituciones especializadas, como huérfanos, abandonados y desvalidos. Trabajando con los discursos productores de conocimiento dirigidos a la gestión de la infancia, constituimos como fuentes no solo los medios de difusión de esos elementos, como tesis, libros y publicaciones periódicas especializadas, sino también los documentos de las instituiciones que informan sobre sus proyectos de reforma y describen prácticas cotidianas, tal como los reglamentos e informes.

\section{PALABRAS CLAVE}

higiene; infancia; internados; Río de Janeiro (1875-1899). 
A constituição de uma racionalidade para a cidade e seus habitantes foi gestada por meio de um complexo institucional no qual se articulam saberes forjados em diferentes campos, como o religioso, jurídico, militar, médico e o da engenharia. ${ }^{1}$ Os empréstimos desenvolvidos entre essas classes foram diversificados e variáveis ao longo do tempo, sendo que, para efeito deste artigo, foi promovido um duplo corte. Trata-se de pensar a modulação do discurso da higiene com base no campo médico, de modo que se observe o ingresso da infância em seu interior como um dos problemas para esse novo saber e as tecnologias aí criadas para lidar com essa "etapa da vida". ${ }^{2}$ Para tanto, centramos nossa atenção no período compreendido entre o fim do Império e início da República, como forma de demonstrar permanências e transformações desse saber, bem como um conjunto de práticas a ele associadas. Procedimento por meio do qual procuramos visibilizar um movimento que se processa sem causalidade única e com efeitos variáveis.

Com base nessa focalização, investigamos a emergência da infância como problema social e também o tratamento formulado ao tema pelos médicos higienistas, formados, em sua maioria, na Faculdade de Medicina do Rio de Janeiro, lugar que proporcionava largo diálogo com a produção dos países considerados modelos de civilização. Ao mesmo tempo, procuramos analisar as marcas dos discursos higienistas em dois internatos públicos criados entre 1875 e 1899, no Rio de Janeiro, dedicados à educação de meninos desvalidos para o trabalho.

Ao trabalhar com a massa de discursos produtores de saberes dirigidos à gestão das infâncias, constituímos como fontes um conjunto heterogêneo de meios de difusão, como teses, livros, periódicos especializados e jornais de grande circulação, mas também documentos de instituições voltadas para o atendimento da criança pobre que informam sobre seus projetos, descrevem práticas cotidianas, indiciam seu funcionamento.

\section{MEDICINA, HIGIENE, INFÂNCIA}

O saber médico preservado e transformado é marcado por mediações complexas entre regimes diversos, com efeitos no próprio funcionamento do campo médico, aqui tomado como forma privilegiada da razão, critério usado até mesmo para se descrever e estratificar os mais variados saberes e práticas vigentes na sociedade brasileira no período examinado.

No mais alto dos estratos deveriam estar os saberes que disputavam o selo ciência, mas que, para serem reconhecidos, exigiam investimento de formação a longo prazo, condição para que essa modalidade de capital cultural pudesse reivindicar para si o estatuto de diretor da vida. Para tanto, os processos de seleção, avaliação e credenciamento são constantes e cada vez mais formalizados na esfera das ordens científicas, entre elas a médica. Por fim, o atestado formal do acúmulo se expressava no diploma.

1 A esse respeito, ver Costa (1989), Gondra (2004) e Laplantine (1991).

2 A respeito da produção da infância, no âmbito de um complexo arquipélago institucional, ver o estudo de Ariès (1981). 
No entanto, ele vem revestido de uma espécie de insuficiência ou de poder provisório, posto que o médico jamais deveria perder contato com seu campo. Nessa linha, outras medidas são tomadas para assegurar a constituição de um grupo profissional, unificado pelas medidas legitimadas em sua interioridade e exterioridade.

A organização da Faculdade de Medicina do Rio de Janeiro, em 1832, constitui-se em marco relevante da história de afirmação da medicina, acoplada, por sua vez, à criação de sociedades científicas, à ação dos médicos na imprensa especializada, na grande imprensa, na literatura e em posições de direção do aparelho estatal, por exemplo. ${ }^{3}$ Esse complexo aparato de poder vai investir o saber médico de uma força suplementar. Nesse sentido, por meio de sinais, como uma arte de conjecturas, a medicina afirma reconhecer a doença, prevendo sua evolução e terapêutica adequada, instituindo-se igualmente como arte necessária para enfrentar determinadas situações convertidas em campo de ação médica. Como prática, é também um exercício capaz de fazer o doente aderir ao diagnóstico e submetê-lo a um novo regime de vida. É precisamente a respeito desse regime de vida que a tarefa da persuasão torna-se mais importante, mais decisiva, já que daí decorre a aceitação de se mudar um conjunto de práticas no que diz respeito a bebidas, alimentos, exercícios, relações sexuais, enfim, todo um modo de vida.

Nesse sentido, trabalhando com conjecturas, em situações bem determinadas, para ser eficaz no combate que promove, a medicina procura cumprir uma função efetivamente educativa. Temos, pois, aqui, uma descrição clássica do campo médico. ${ }^{4}$ No entanto, para a higiene, a medicina multiplicaria sua potência e seria ainda mais eficaz quando pudesse evitar o aparecimento da doença - procedimento este que supõe um alargamento do raio de ação da ciência médica, configurando a higiene como ramo desse saber que se ocupa da prevenção. Dessa forma, sob o arco dessa ciência que se pretendia ver expandido, procurou-se instalar um conjunto de instituições e práticas como as desenvolvidas em igrejas, quartéis, prisões, hospícios, bordéis, oficinas e escolas.

Ao incidir sobre as escolas, a higiene se pautou em um projeto de larga tradição, voltado para a educação física, moral e intelectual, isto é, a chamada educação integral, em que cada um desses eixos se viu submetido a um detalhamento minucioso, orientado pela racionalidade médico-higiênica. Sonos, banhos, vestimentas, alimentos, excreções, iluminação, entre outros, nada parecia (ou deveria) escapar ao crivo do saber-poder médico. Ao lado disso também se fez necessário definir onde, quando e durante quanto tempo a intervenção sobre os sujeitos (e a população) deveria ser promovida e, do mesmo modo, o equilíbrio e a dosagem das medidas a serem adotadas.

Para efeito deste trabalho, tomamos como indicador dessa racionalidade as definições acerca do início da ação educativa pautada na racionalidade médica. Afinal, quando a escolarização deveria ser iniciada? Pergunta que mobilizou a comunidade no intuito de se produzir uma espécie de consenso. Para tanto, saberes diversos da anatomia, fisiologia e neurologia foram mobilizados para se definir a boa idade de educar. Em outras

3 Para se ter noção das práticas médicas anteriores à criação das faculdades de medicina no Brasil, ver Santos Filho (1991).

4 A esse respeito, ver Foucault (1994, 2006, 2008). 
palavras, procurou-se estabelecer um saber sobre a vida, produzindo uma espécie de gradiente, inscrito em um ciclo fechado, do nascimento à morte. Nele, variações, etapas, idades da vida, cada qual submetida a uma descrição detida, procurando tornar possíveis determinadas ações. O que se perseguia era uma ciência dos corpos, mas também uma ciência das almas que, bem articuladas, funcionaria como guia seguro para se produzir o homem educado, pautado nos procedimentos preventivos da higiene.

Perspectivada nesses termos, a infância vai emergir como um problema para o campo médico. Problema este que supõe um recuo ao tecido familiar e ao casamento do qual poderia advir um ser saudável. Assim regulada, a célula familiar se viu instalada no horizonte do saber médico como condição para assegurar gestação, nascimento, sobrevivência e prolongamento da vida e, do mesmo modo, um conjunto de outras instituições foi colocado no raio de ação desse saber como uma espécie de complemento e, por vezes, antídoto da casa, entre elas a escola (Costa, 1989; Machado et al., 1978).

Mas, afinal, quando dar início à forma de educação escolar e durante quanto tempo? Sob que procedimentos? Conduzida por que tipo de agente? Em que espaço? Que tipo de saber difundir? Trata-se, como se pode observar, de um largo questionário que incide sobre algumas das propriedades gerais da escola.

Nesse sentido, nem a escola nem o objeto da escolarização podem ser tomados como um dado, um modelo geral, dotado de uma espécie de universalidade, neutralidade e perenidade. Como explorar essas variações? Como tornar perceptível e pensável as diferenças dessa moderna tecnologia? Neste texto, procuramos dar visibilidade ao modo como o saber médico procurou constituir regras para lidar com a infância, sobretudo a infância pobre.

\section{UM SABER OCIDENTALIZADO}

Formados no Brasil, mas também em Paris, Montpellier, Porto ou Lisboa, alguns homens da ciência médica introduziram o tema da infância no arco de suas preocupações, decisão que, por sua vez, instaura as famílias e outras instituições educativas na larga gramática articulada pelo campo médico. ${ }^{5}$

Em uma das primeiras teses apresentadas e sustentadas na Faculdade de Medicina de Montpellier, em 1798, Vital-Louis Joyeux abordou o tema da infância e o modo de se lidar com esse corpo. ${ }^{6}$ Intitulada Considérations directes et indirectes sur quelques points de l'éducation physique des enfants, em suas trinta e duas páginas a tese

5 Para o caso europeu, ver detalhes na coletânea organizada por Becchi e Julia (1998), no dossiê "Cuerpo, Higiene, Educación e Historia", organizado pela revista Historia de la Educación, Universidade de Salamanca (2009), nos trabalhos de Pedro Moreno Martínez (2006, 2009a, 2009b), e no do trabalho de Bakker (2006) sobre o processo de medicalização da infância nos Países Baixos.

6 Essa preocupação vai permanecer na ordem médica. A esse respeito, em Montpellier, conferir as teses de Aimé Paloque (1863), Alphonse-Louis Blanc (1869), Jules Caillat (1846) e Léon-Paul-Félix Evesque (1863); por exemplo. Para o caso português e brasileiro ver Ferreira e Gondra (2006) e Pereira e Pitta (1993). 
procura consolidar um saber, ${ }^{7}$ adequando-o aos procedimentos dessa modalidade de escrita, nessa condição particular. ${ }^{8}$

Ao iniciar o texto, o autor define o duplo objeto da educação: dar ao corpo a força que ele deve ter e aperfeiçoar as faculdades da alma. Ao assinalar a extensão desse programa educativo, indica o corte no qual trabalha: a questão do corpo. No caso, a intenção é pensar os melhores meios para formar crianças robustas e vigorosas. Para atingir essa finalidade, defende uma educação presente desde o momento da concepção, ocasião em que os "deveres da maternidade" deveriam ser iniciados. Com isso, em nome da "felicidade da sociedade", demanda das mulheres uma escuta atenta aos conselhos contidos na tese, pois é delas esse primeiro dever $-{ }^{9}$ que seria mais bem cumprido seguindo-se os sábios preceitos da medicina em relação à maneira de viver.

Em que consistiria esse regime? Alinhado aos princípios doutrinários da higiene e recorrendo ao discurso da persuasão, as mulheres grávidas deveriam observar diferentes aspectos, tais como respiração, temperatura, alimentação, bebidas, exercícios, roupas, paixões, sexo, odores e sono, para assegurar certa conduta ajustada ao seu dever - que prossegue com os cuidados a serem dispensados ao filho. Nesse caso, tendo no horizonte a robustez e vigor do corpo, os conselhos médicos incidem sobre o aleitamento, com uma defesa vigorosa em favor da amamentação natural; sobre o enfaixamento, em uma crítica contundente a essa prática, descrita como bárbara; roupas e banhos. No limite, organizada em torno dos conselhos formulados, apoiada em bibliografia e nos exemplos e contraexemplos da história, a ciência se mostra a serviço da natureza, de modo que o corpo pudesse se desenvolver naturalmente.

Nesse aconselhamento geral, as mulheres aparecem como destinatárias privilegiadas. No entanto, trata-se de conselho para todos, posto que um conjunto de ações associadas ao feminino integra uma comunidade de outros agentes para os quais o discurso médico também se volta, de modo que assegurasse a efetividade da norma nele contida.

Os princípios gerais da tese do doutor Vital-Louis Joyeux são retomados em um conjunto expressivo de teses na Faculdade de Medicina de Montpellier, Paris, Porto,

7 Um indício do corpo de saberes que modela a reflexão pode ser percebido nos saberes ensinados durante o curso de formação (medicina legal, fisiologia e anatomia, química, matéria médica e botânica, patologia, medicina operante, clínica interna, clínica externa, partos, doenças femininas, educação física das crianças e demonstração de drogas usuais) e nos rebatimentos promovidos no interior dessa escrita (Andry, Baumes [Jean Baptiste Timothée], Buffon, Demóstenes, Dumas [Charles Louis], Grimaud, Galien, Hipócrates, Locke, Montaigne, Plutarco, Raynal, Rousseau, Sennert, Tácito, Vanhelmont, Vigaroux [Joseph Marie Joachim], Winkelmann). Nota-se que o repertório remete a professores (Dumas, responsável pela cadeira de fisiologia e anatomia; Vigaroux, pela cadeira de partos; e Baumes, pela cadeira de patologia) e a autores que ajudam a fortalecer a crença na razão.

8 A tese encontra-se estruturada em duas partes. A primeira, com dois capítulos, trata da questão da gravidez. Na segunda parte, o foco recai sobre o recém-nascido, os cuidados, as roupas, aleitamento, alimentação e banhos.

9 Aqui, apoia-se literalmente no livro Emílio, de Jean-Jacques Rousseau: "A primeira educação é a que a mãe imporá, e a primeira educação pertence incontestavelmente às mulheres". 
Lisboa, Salvador e Rio de Janeiro. ${ }^{10}$ Com isso, procura-se afirmar e intensificar a perspectiva da prevenção, que, no caso, vem acompanhada de roteiro meticuloso que instaura a vida em um fabuloso quadriculado. Nesse caso, cumpriria observar um conjunto de aspectos que definem o regime da vida: circumfusa (ar, água, lugares); applicata (roupas, banhos, loções, fricções); ingesta (alimentos e bebidas); excreta (excreções); gesta (exercício, repouso, sono e vigília); e percepta (afetos da alma, as paixões). ${ }^{11}$ Instalado nessa espécie de hexágono, acompanhando o conjunto detalhado das prescrições rebatidas em cada um de seus vértices e observando as articulações de cada ponto entre si, é que, na lógica do discurso médico, se estaria praticando uma educação integral. ${ }^{12}$

Mas o quadriculamento supõe outras dobras. A própria unidade da ideia de infância, associada a uma etapa da vida, apaga-se ou se vê esmaecida com as repartições internas dessa etapa. ${ }^{13} \mathrm{~A}$ título de exemplo, sinal de uma tradição que pretende isolar cada vez mais agregados populacionais, para melhor conhecer e conduzir, podemos observar um detalhamento a respeito das partes da vida na tese apresentada por Marc-Antoine Lautaret, em 1802, intitulada Quelques considérations générales sur l'éducation physique des enfants. ${ }^{14}$ Para ele, a infância se constitui na primeira fase da vida, indo do nascimento até a puberdade - 12 a 14 anos no caso das meninas e 14 a 16 anos no caso dos meninos, nos países temperados. ${ }^{15} \mathrm{~A}$ infância, por sua vez, divide-se em primeira e segunda fase. A primeira compreende o intervalo que vai do nascimento até a época da segunda dentição, isto é, em torno dos 7 anos. Já a segunda se estenderia até a puberdade.

Essa divisão inicial, contudo, admite outras subdivisões para melhor definir a educação física própria a cada etapa da vida. Para o médico de Montpellier, a primeira infância se subdivide em três épocas, ${ }^{16}$ cada qual correspondendo a características específicas:

10 Uma pequena lista de teses defendidas em Montpellier e Paris pode ser consultada no final deste artigo. Para o caso de Brasil e Portugal, ver Gondra (2004) e Ferreira e Gondra (2006).

11 Para o caso da higiene corporal na França, ver Vigarello (1996) e, para o caso português, Crespo (1990).

12 O projeto de educação integral conheceu uma difusão importante por meio do trabalho de Spencer (1886), publicado pela primeira vez em 1863. Não partilhamos, contudo, da tese que atribui ao pensador inglês a originalidade dessa formulação. Em nossa perspectiva, ele integra uma cadeia discursiva que mobiliza agentes diversos e bem anteriores à sua própria produção.

13 A oscilação dos limites temporais definidores da infância esbarra em variação equivalente para se definir os limites do ser jovem. A esse respeito, Levi e Schmitt (1996) insistem no fato de que a "juventude" por eles estudada não encontra definição clara nem na quantificação demográfica, nem na definição jurídica. Para a questão das etapas da vida, ver Chauvin (1996).

14 Ao iniciar, o autor chama a atenção para a existência de duas classificações relativas às idades da vida; uma que trabalhava com quatro e outra com cinco períodos.

15 Essa fase é caracterizada por uma pele mole e fina, volume da cabeça mais considerável com relação às outras partes, flexibilidade dos membros e um sistema nutritivo mais ativo que em outras idades.

$16 \mathrm{O}$ médico não apresenta subdivisão para a segunda infância. 
- Primeira: do nascimento até os 7 meses;

- Segunda: do aparecimento dos primeiros dentes até o fim da primeira dentição;

- Terceira: do fim da primeira dentição até os 7 anos.

Aqui, algumas observações: a variação da idade conforme o gênero e clima na segunda infância e a supressão dessas variantes na primeira idade. O que pode explicar essa distinção? A hipótese sugere uma direção semelhante na primeira idade, "a idade da casa", do mundo privado, doméstico. A educação escolar, por sua vez, deveria instalar em seu horizonte essas variáveis, sugerindo acomodações dos programas educativos aos climas e aos sexos. ${ }^{17}$ Com esse esforço de classificação, a higiene pretendia definir, de modo mais preciso, as qualidades do corpo para estimular os atributos vantajosos e inibir os perniciosos. Para tanto, cabia à higiene interferir nas "coisas chamadas não naturais", como os ares, lugares, águas, excreções, retomando, assim, o programa contido na tese de 1798 de seu colega de faculdade.

Nesse movimento oscilatório, nas variações relativas às idades da vida é o arbitrário da razão que se vê matizado, na medida em que busca elementos gerais que possam funcionar como critérios de fácil verificação - base para se construir e sustentar a tese de frações homogêneas da vida, derivada dos atributos físicos dos sujeitos. No entanto, a dimensão física das classificações das idades da vida se faz acompanhar de observações de caráter social. Trata-se, portanto, de um argumento adicional para segmentar e propor determinadas experiências para as crianças marcadas por seus caracteres físicos, mas também por condições sociais distintas.

Desse modo, a própria medicina vai sublinhar a existência de desequilíbrios no tecido social e dos limites de tal discurso perante o que se descreve como situações de miséria. Nesse caso, como assegurar a positividade das intervenções médicas? Para tanto, a pobreza também precisava ser medicalizada, de modo que protegesse e defendesse a sociedade dos perigos que representava. ${ }^{18}$

Articuladas, essas duas presenças - infância e pobreza - configuram uma classificação da vida e tipo de experiência a ser facultado ao que se considera infância de

17 Aqui não é possível avançar na questão. Cabe apenas registrar a variação da idade como marcadora do início da puberdade. Representada como a "idade das paixões” e/ou “idade dos perigos", as diferenças apontam para cuidados extras a serem adotados ao se atingir essa idade da vida nas experiências distintas decorrentes dos países e climas, por exemplo.

18 No Rio de Janeiro, ao discorrerem sobre o tema da infância, torna-se perceptível a preocupação dos médicos com as crianças submetidas a condições desiguais. No caso dos discursos autorizados pela Faculdade de Medicina do Rio de Janeiro, isso pode ser evidenciado no conjunto de cinco teses que abordam o ponto das "crianças expostas”. Trata-se dos trabalhos de Francisco de Paula Lazaro Gonçalves (1855), Manoel Velloso Paranhos Pederneira (1855), Thomaz Baptista Pinto D'Almeida (1857), Luiz Delfino dos Santos (1857) e José Alexandre Teixeira de Mello (1859), todas elas intituladas Criação dos expostos da Santa Casa da Misericórdia. Para conhecer a coleção de teses da Faculdade de Medicina do Rio de Janeiro, ver Catálogo de teses da Universidade Federal do Rio de Janeiro (1986). 
ouro, prata ou bronze. ${ }^{19} \mathrm{O}$ serviço prestado por essa inteligência estratifica sujeitos e instituições, procurando o ajustamento de uns e outros. Com essa forma de exercício de poder, o que se pretende? $\mathrm{O}$ alcance do bom governo a ser atingido por uma espécie de naturalização do regime geral a que todos são submetidos. Nessa economia política, a produção de uma unidade plural e diferenciada tende a se apresentar mais forte ao se identificar um inimigo comum. Nesse e em muitos outros casos, a desordem, barbárie ou doença são convertidas a esse "comum" a ser combatido. Nessa compreensão, o enfrentamento do mal seria mais eficaz no interior de uma ordem estratificada, na qual cada um, cada parte, como em um corpo, sinfonia ou federação, ao bem exercer sua função, asseguraria o sucesso do conjunto.

No caso da infância pobre, é sua família ou sua ausência que é representada como fonte de perigo. É também aquilo em que a criança pode se converter. Trava-se, desse modo, um combate que visa amenizar, retardar ou erradicar os riscos do presente, mantendo o caráter de prevenção social das medidas prescritas. Voltando-se para a criança e sua família, as formas de combate são diversas. No caso da criança pobre, uma das mais difundidas é a forma asilar, que, no geral, busca cumprir uma tripla função: casa, oficina e escola (Souza, 2008). Essa forma de combate conheceu ampla disseminação na Europa e nas Américas, para a educação de crianças de diferentes origens étnicas, devendo-se, contudo, considerar os ritmos, funcionamentos e efeitos das formas asilares destinadas à infância pobre no Brasil e nas demais realidades em que foram praticadas.

Entre as últimas décadas do século XIX e princípios do XX, é possível perceber na documentação dos internatos de formação para o trabalho manual os efeitos dos discursos médicos sobre a reforma das instituições educacionais e de seus processos pedagógicos. Para demonstrar como se operam os dispositivos (médicos) de conhecer, classificar e intervir sobre a infância no cotidiano de duas instituições educacionais, tomaremos como exemplo dois internatos: um criado ainda sob o regime imperial (Asilo de Meninos Desvalidos, 1875) e outro sob o republicano (Escola Quinze de Novembro, 1899).

\section{INTERNAR E EDUCAR SEGUNDO OS PRECEITOS HIGIÊNICOS: EXPERIÊNCIAS NO IMPÉRIO E NA REPÚBLICA}

No século XIX e princípios do XX, o tema da educação integral ocupou a agenda de algumas categorias profissionais, como os médicos higienistas e autoridades dos governos imperial e republicano. Neste trabalho, as repercussões dos debates sobre os asilos para a infância pobre são analisadas com base em duas experiências específicas: as práticas educacionais engendradas no Asilo de Meninos Desvalidos, fundado em 1875 na Corte, pelo governo imperial, e a Escola Quinze de Novembro, fundada em 1899, na cidade do Rio de Janeiro. Esta resultou de uma iniciativa particular do chefe

19 Para Varela e Alvarez-Uria (1992), de modo geral, pode-se falar de uma infância de "ouro, prata e bronze" para distinguir as propriedades materiais e capital cultural associados a cada um desses tipos. 
de polícia João Brasil Silvado, preocupado em dar um destino aos meninos recolhidos que fosse coerente com os ideais identificados com o novo regime político do país. Em poucos anos, o governo federal encampou a instituição com a aprovação do regulamento de 1903, transferindo-a, em 1907, para uma antiga fazenda nos subúrbios da cidade. ${ }^{20}$

A ênfase dos discursos, especialmente os produzidos por médicos, sobre a má localização das escolas e da insalubridade da Corte Imperial parece ter influenciado a decisão dos governantes na escolha do bairro de Vila Isabel, distante do núcleo urbano, para abrigar o Asilo dos Meninos Desvalidos. A partir de 1880, a direção do asilo foi entregue a médicos formados pela Faculdade de Medicina do Rio de Janeiro, como João Joaquim Pizarro (de 1880 a 1883) e Daniel Oliveira Barros de Almeida (de 1884 a 1889) (Souza, 2008). ${ }^{21}$

A instituição atendeu a uma parcela de meninos desamparados do município em sua ampla chácara, cujo complexo arquitetônico abrigava um imponente palacete. Esses meninos tiveram destino diferente da maior parte dos recolhidos pela polícia para a Casa de Detenção, ${ }^{22}$ entre as décadas de 1870 e 1880 . No processo de reordenamento da cidade, que pressupunha uma redistribuição das infâncias, os meninos identificados como "menores", recolhidos à detenção, foram entregues a fazendeiros e enfrentavam o trabalho forçado junto com a escravaria das fazendas de café do interior do Rio de Janeiro. $^{23}$

As concepções de educação vigentes, atentas a uma "nova pedagogia" ${ }^{24}$ e às contribuições das ciências, colaboraram na construção do projeto pedagógico do Asilo dos Meninos Desvalidos, a começar pela escolha do local, feita em absoluto respeito às prescrições higiênicas. $\mathrm{O}$ ideal de formação, ancorado nos preceitos higienistas, contemplava a educação física, intelectual e moral - aspectos complementares de uma educação integral (Gondra, 2004).

Tais preceitos, aplicados às "camadas inferiores" da sociedade, traduziam-se no preparo intelectual prático, voltado para as necessidades do trabalho, no fortalecimento do corpo, por meio dos exercícios ginásticos e militares e da formação moral.

20 Trata-se de documento composto por setenta e cinco artigos, no qual a instituição aparece vinculada ao Ministério da Justiça e à polícia, por meio de uma série de determinações que dialoga com os preceitos higiênicos e pedagógicos a respeito dos cuidados e da educação dos menores internados, caracterizando-se como "estabelecimento destinado à reabilitação e à prevenção dos menores abandonados” (Brasil, 1903, texto inicial).

21 Pizarro era médico e cirurgião da Marinha Brasileira, catedrático em zoologia e botânica (1882) e chefe da seção de zoologia e anatomia comparada do Museu Nacional (Souza, 2008, p. 48). Daniel Almeida era bacharel em medicina e filho do primeiro diretor do Asilo de Meninos Desvalidos, Rufino Augusto de Almeida, que, antes de mudar-se para o Rio de Janeiro, dirigiu a Casa de Correção de Pernambuco, uma instituição prisional (idem).

22 A Casa de Detenção da Corte possuía regime prisional, com uma seção separada para "menores delinquentes".

23 O relatório do Ministério da Justiça de 1877 informa que 333 dos 395 menores de "vida errante, sem o freio da educação", recolhidos à Casa de Detenção, foram entregues a alguns fazendeiros (Brasil, 1878, p. 37).

24 A respeito, ver o relatório do ministro do Império, Rodolpho de Souza Dantas, em que defende os ideais de uma pedagogia moderna (Brasil, 1882, p. 5). 
$\mathrm{Na}$ experiência do Asilo dos Meninos Desvalidos, a aplicação da educação integral articulava três dimensões: casa, escola e oficina. Outras instituições do gênero, como as primeiras casas e institutos de educandos artífices, também funcionavam apoiadas nesses três princípios gerais. Mais uma vez, cabe sublinhar que esse traço comum não permite afirmar que tenha havido um funcionamento homogêneo dos diferentes estabelecimentos construídos no Brasil para o atendimento da criança pobre.

Abrigar, instruir e profissionalizar os meninos "desvalidos" era função do Asilo. Essa tripla função impunha relações diferenciadas com a estrutura do Estado imperial. As funções de abrigamento/moradia (casa) e formação para o trabalho (oficina) faziam com que o Asilo ficasse atrelado à Inspetoria de Higiene e Assistência. A escola, por sua vez, vinculava o Asilo à Inspetoria de Instrução Primária e Secundária do Município da Corte. Esse duplo pertencimento revela a tensão entre o educacional e o assistencial no âmbito das finalidades institucionais do Asilo, para o qual foram adotadas formas diferenciadas de ordenamento. Somente em 1894, quando o Asilo torna-se o Instituto Profissional, o ensino integral é previsto em novo regulamento (decreto n. 31, de dezembro de 1894, apud Fonseca, 1897). O regulamento passa, então, a reconhecer legalmente uma concepção educativa que já orientava as práticas pedagógicas da instituição há duas décadas (Rizzini; Souza, 2009).

O período adotado pelas instituições para o início da ação educativa não desmentia a pauta médica: a internação ocorria entre 6 e 7 anos, quando a criança era iniciada no aprendizado das primeiras letras nas salas de aula instaladas no interior dos asilos. O treinamento para o trabalho deveria ser adiado até a idade em que o menino tivesse a robustez suficiente para suportar as exigências do trabalho manual nas oficinas e no campo. A entrada na puberdade anunciava o tempo do trabalho, e, se nas escolas regulares, as fotografias das salas de aula em atividade representavam o labor educativo, nos internatos as fotografias dos aprendizes trabalhando nas oficinas surgiam como um meio de afirmação de sua identidade educacional: formar trabalhadores dedicados aos seus deveres.

Nas etapas da vida, o espaço de aprender requeria especializações e divisões conforme a visão dos médicos, educadores e gestores -, que ocorriam no interior das instituições por meio da ocupação do tempo e da atividade a ser desempenhada, com o ensino e o trabalho graduados, de acordo com as faixas de idade. Mas também requeria hierarquias e divisões, estas criadas por meio do estabelecimento de instituições especializadas por faixas de idade, de 6 a 12 e de 12 a 21 anos, formando uma rede de assistência à infância desvalida em respeito às fases da vida. A criação da Casa de São José na cidade do Rio de Janeiro, em 1888, permitiu ao Asilo de Meninos Desvalidos dedicar-se exclusivamente ao ensino profissional de jovens rapazes, que nele deveriam ingressar entre 12 e 14 anos e permanecer até a idade de 21 anos. Posteriormente, a idade-limite é reduzida para 18 anos, constituindo ciclos de formação a duração de seis anos cada (Rio de Janeiro, 1911).

Os dous estabelecimentos se completarão mutuamente, sendo recebidos: na Casa de S. José os menores de 6 annos até 12, e no Asylo de Meninos Desvalidos os dessa idade até 14 annos. (Brasil, 1890, art. 4) 
$\mathrm{Na}$ Casa de São José, os pequenos eram iniciados nas letras e nas habilidades valorizadas para o trabalho manual, como o aprendizado do desenho. ${ }^{25}$ Os professores desenvolviam um saber de observação das destrezas e aptidões de seus alunos, de modo que o diretor pudesse indicar os escolhidos para serem transferidos para o Asilo dos Meninos Desvalidos. O Asilo, como outras instituições educacionais do Império, manteve suas ações no alvorecer do regime republicano. Podemos então perguntar: $\mathrm{O}$ que passa a ser representado como novo nos cuidados à infância pobre sob os auspícios do novo regime?

Em primeiro lugar, um ardoroso combate às práticas identificadas com o atraso, como o enclausuramento com adultos dos chamados menores vadios, vagabundos, viciosos e delinquentes, todos apreendidos pelas ações policiais de "limpeza" das ruas das cidades. ${ }^{26}$ Em seguida, as críticas ao caráter de clausura desses "depósitos” sem as finalidades de regeneração, recuperação e reeducação dos internos, de modo que os tornassem úteis à pátria. $\mathrm{O}$ ideário da introdução de noções de cunho cientificista nas instituições que atendiam a essa população torna-se uma bandeira de luta nas décadas seguintes, liderada por autoridades e reformadores de grande notoriedade na época, como juristas e médicos higienistas.

Atento aos ideais de educação/regeneração da infância em perigo, o chefe de polícia do Rio de Janeiro fundou, em 1899, uma "escola" dirigida especialmente às crianças que seus subordinados recolhiam cotidianamente nas ruas da cidade. Na escola, que levou em seu nome a data da proclamação da República, os internos aprendiam a gramática portuguesa, matemática, desenho, noções de artes e música, além dos exercícios ginásticos, ofícios mecânicos e trabalhos agrícolas. Tratava-se de uma formação centrada nas atividades laborais, como o trabalho nas oficinas e no campo, tendo em vista a "gente desclassificada" a que se destinava a instituição. Ao lado do caráter preventivo, a formação de trabalhadores também visava às demandas incipientes de industrialização. Nesse cenário, a colocação mais elevada para o "menor" implicava obter o estatuto de operário.

Esse projeto geral, de sua parte, supunha estratificações internas ao prever que os "menores" que revelassem "dotes superiores" poderiam continuar a formação em nível secundário ou no ensino artístico em estabelecimentos mantidos pela União, como se pode ver no que se encontra delineado no regulamento da Escola Correcional Quinze de Novembro.

Sendo a Escola destinada à gente desclassificada, a instrução ministrada na mesma não ultrapassará o indispensável à integração do internado na vida social. Dar-se-lhe-á, pois, o cultivo necessário ao exercício profissional. Aqueles indivíduos, porém, que revelarem dotes superiores, durante ou no fim do estágio,

25 O decreto n. 282, de 27 de fevereiro de 1902, confere à Casa de São José o caráter de "curso de adaptação" ao Instituto Profissional Masculino (ex-Asilo de Meninos Desvalidos).

26 Desde a criação da chefia de polícia, no século XIX, até a instalação dos juizados de menores a partir da década de 1920, coube à instituição policial a apreensão de "menores" nas ruas. A esse respeito, ver Schueler e Rizzini (2007) e Vianna (1999). 
serão admitidos a qualquer estabelecimento de ensino secundário ou artístico custeado pela União. (Brasil, 1903, art. 3º)

Nos relatórios de Franco Vaz (1905, 1914), secretário e posteriormente diretor da escola, a transformação dos desclassificados aparece no registro fotográfico (Imagens 1,2,3 e 4). A preocupação com a prova da eficácia do processo educacional é patente, seja por meio de fotografias dos internos, seja pelos próprios relatos dos alunos, em cartas e inquéritos.

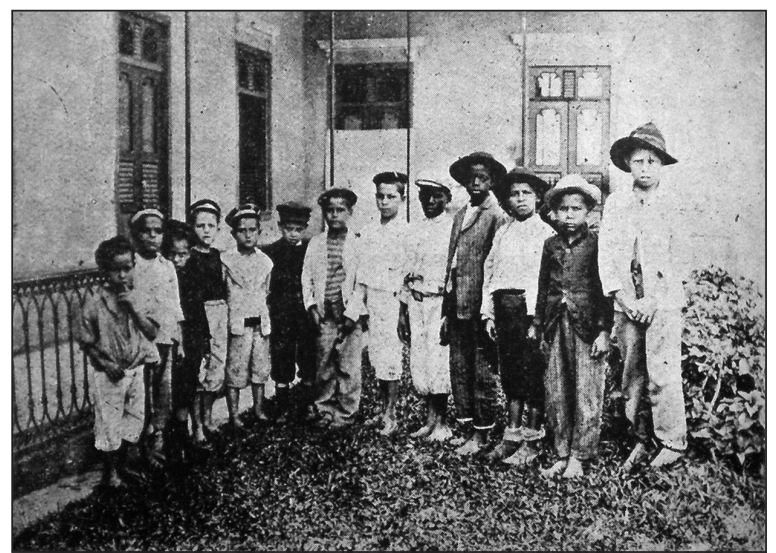

Imagem 1 - Escola Premunitória Quinze de Novembro. "Grupo de menores ao chegarem à escola a fim de serem matriculados” (1913).

Meninos recolhidos pela polícia nas ruas da cidade do Rio de Janeiro chegam à instituição para serem transformados em bons trabalhadores.

Fonte: Vaz, 1914, p. 72.

Elaboração dos autores.

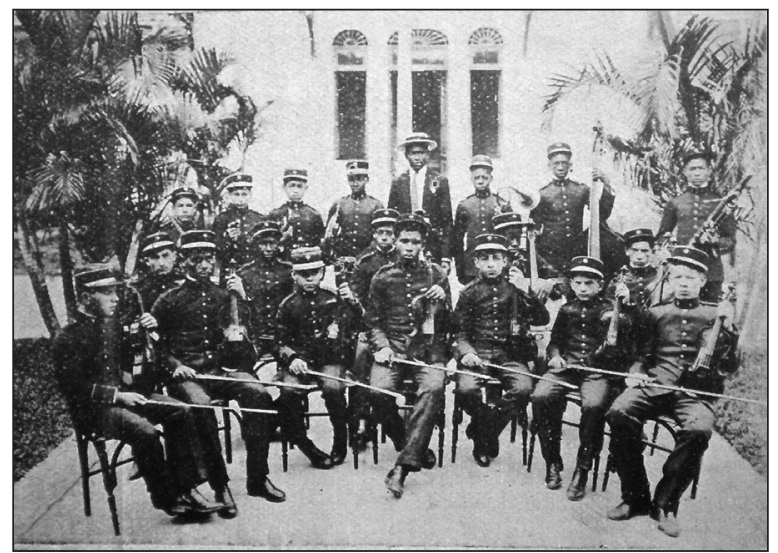

Imagem 2 - Escola Premunitória Quinze de Novembro. “Orquestra de alunos”(1913).

Os alunos da orquestra, vestidos com o traje para apresentações em público,

tinham como mestre um ex-aluno da Escola Premunitória.

Fonte: Vaz, 1914, p. 41.

Elaboração dos autores. 


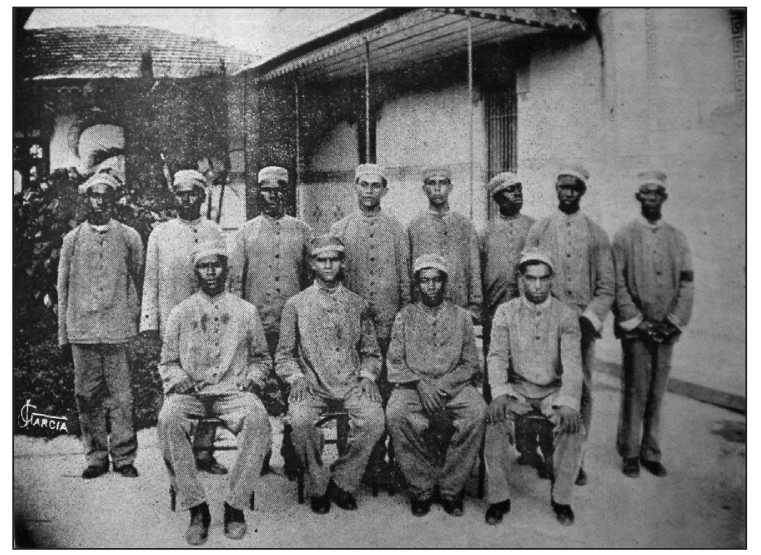

Imagem 3 - Escola Premunitória Quinze de Novembro.

"Alunos contramestres das oficinas" (1913).

O grupo de internos uniformizados e calçados contrasta com os trajes e pés

descalços dos meninos quando chegam à escola, retratados na Imagem 1.

Após anos de formação, os alunos contramestres auxiliam os mestres no trabalho nas oficinas e no treinamento dos iniciantes.

Fonte: Vaz, 1914, p. 83.

Elaboração dos autores.

Na gestão do poeta e literato Franco Vaz, em meados da década de 1910, a instituição também incorporou os preceitos higienistas à formação escolar dos educandos. ${ }^{27}$ O diretor integrou ao currículo escolar a disciplina higiene, ministrada pelo médico da escola, disposição confirmada pelo registro nas folhas de pagamento de pessoal de 1913, nas quais constam os salários pagos ao doutor Álvaro Reis na condição de auxiliar de ensino. $^{28}$

A matriz curricular atendia aos princípios da educação integral preconizada pelos higienistas, contendo disciplinas que abarcavam a formação intelectual, física e moral. O projeto n. 322, de 1912, que "reorganiza o ensino da Escola Quinze de Novembro e dá outras providências", ${ }^{29}$ previa a introdução de novas disciplinas, como história do Brasil, geografia, geometria, lições de coisas, instrução moral e cívica e higiene. Trata-se

27 Não consta nas fontes que Franco Vaz tivesse se diplomado em nível superior. No verbete da Enciclopédia de literatura brasileira (Coutinho; Sousa, 2001, p. 1.609), Franco Vaz é apresentado como "poeta, romancista, cronista, cientista, repórter, jornalista", tendo publicado obras literárias e trabalhos sobre a "infância abandonada e delinquente".

28 Arquivo Nacional, série Justiça, Escola Quinze de Novembro, folha de pagamento do pessoal sem nomeação (1913). Segundo Vaz (1913, p. 8), o médico Álvaro Reis dedicava-se à clínica infantil como assistente do Hospital das Crianças do Rio de Janeiro, além de ocupar a função de professor de "higiene alimentar" da Escola Quinze de Novembro. Autor de diversos artigos e textos sobre a "infância abandonada", higiene escolar e outros trabalhos que associam a higiene à educação dos desvalidos e dos escolares, Reis atuou em várias instituições médicas e no ensino superior ao longo de sua carreira (Sobrinho, 1940).

29 Disponível em: <http://www.ciespi.org.br/base_legis/baselegis_view.php?id=254>. Acesso em: maio 2014. 
de uma matriz que, ao introduzir esses saberes, valoriza um corpo de conhecimentos de caráter menos utilitário, redesenhando, assim, a educação dos internos.

No relatório atinente ao ano de 1913, o diretor afirma que "continuou a ser distribuído com perfeita regularidade o ensino literário dos educandos, nos três estágios do curso - elementar, médio e complementar -, de acordo com o programa de ensino adotado em outubro de 1912" (Vaz, 1914, p. 47), não se furtando de publicar uma fotografia da sala de aula (Imagem 4) ${ }^{30}$ Cumpre notar que o realinhamento da instituição parece estar associado à rede de relações das quais participavam o diretor e o médico. Ambos se encontravam envolvidos nos debates travados entre os grupos intelectuais e profissionais dedicados ao tema da infância abandonada. Juntos também editaram a revista Educação e Pediatria, na qual eram publicados artigos de profissionais e autoridades, incluindo os médicos higienistas. ${ }^{31}$

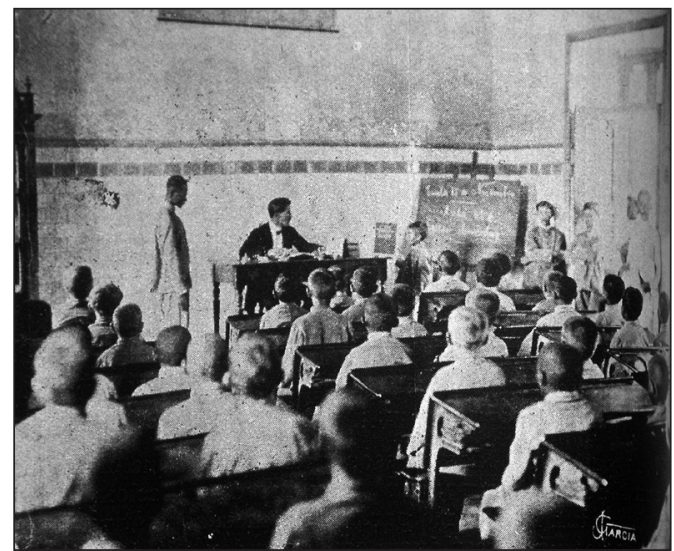

Imagem 4 - Escola Premunitória Quinze de Novembro. "Aula de analfabetos e menores que apenas conhecem os primeiros rudimentos". No interior das instituições asilares, as crianças frequentavam as salas de aula sem o risco das vadiações pelas ruas da cidade. Fonte: Vaz, 1914, p. 50.

Elaboração dos autores.

30 A divisão do ensino em três níveis estava prevista no artigo $1^{\circ}$ do projeto n. 332, debatido na sala das sessões do Congresso Nacional, em 14 de setembro de 1912. Nota-se que, embora o projeto não tenha sido transformado em lei, Franco Vaz introduziu mudanças no ensino da Escola com base nesse documento.

31 Vaz e Reis eram "diretores e proprietários” da revista mensal Educação e Pediatria, na qual eram publicados artigos de colaboradores das mais diversas áreas, tais como a jurídica, médica, literária e educacional. A revista teria sido lançada em 1903-1904 e relançada em 1913. Na Fundação Biblioteca Nacional, localizamos exemplares apenas dos anos de 1913 a 1916, totalizando vinte e nove números. 
Se no século XIX os asilos circunscreveram os critérios de matrícula às características do educando, tais como ter boa saúde, ser vacinado, pobre e livre, no início do regime republicano acrescentou-se à avaliação médica do "menor" a investigação da hereditariedade. ${ }^{32}$ Tendo em vista o combate a um possível processo degenerativo do interno, especialmente para os casos de instituições que recebiam crianças recolhidas nas ruas pela polícia, o médico era o responsável pelo preenchimento da "ficha sanitária" dos recém-chegados.

Por meio desse instrumento, o médico perscrutava a vida atual e pregressa dos sujeitos e de seus familiares, na busca por fatores hereditários que pudessem comprometer o processo educativo a que seriam submetidos na instituição. Ao produzir um conhecimento dos antecedentes "patológicos" do interno, o médico poderia prescrever que "esse menor fosse vigiado com solicitude e cuidado, com carinhos especiais" (Relatório do chefe de polícia ao ministro da Justiça e Negócios Interiores, 1911, p. 48 apud Vianna, 1999, p. 148). A mudança do nome da instituição (de Escola Correcional para Escola Premunitória) já indica a disposição de seus gestores para abraçar o preceito médico da prevenção, no sentido moral, já que, com seus dispositivos de identificação, vigilância e intervenção sobre os desvios, a escola atuaria no intuito de prevenir desordens sociais, incluindo a criminalidade.

Circulava entre os grupos comprometidos com a "causa da infância" uma forte crença de que "a educação é o antídoto da criminalidade", cabendo ao Estado não estender os aparelhos judiciários ou policiais, mas disseminar os aparelhos educativos. Fora o que defendera Franco Vaz (1917, p. 17) na Conferência Judiciária-Policial, reunida no Rio de Janeiro em 1917, apropriando-se de mais um termo médico. Além dos textos dos congressos, dos periódicos e livros dedicados ao tema da infância, circulavam entre os grupos intelectuais e autoridades públicas outros tipos de materiais, como os relatórios de determinados setores do governo. Os relatórios da Escola Premunitória Quinze de Novembro, impressos na tipografia da instituição pelos próprios educandos, não estavam confinados à função burocrática de prestação de contas ao Estado. Nesses documentos, os gestores expunham suas bandeiras de luta pela causa da infância brasileira, abraçando projetos de reforma que iam além da instituição a que se encontravam vinculados. ${ }^{33}$ Valendo-se de um dos relatórios de Franco Vaz, elaborado em 1912, o conhecido jurista Ataulpho de Paiva (1916, p. 147) clamou pela criação de outras instituições do gênero, destacando a trágica situação educacional da cidade. ${ }^{34}$

32 Para uma análise das teorias raciais e hereditariedade no Brasil, entre os séculos XIX e XX, ver Schwarcz (1995).

33 Um exemplo notório é o relatório encomendado pelo ministro da Justiça a Franco Vaz e publicado pela Imprensa Nacional em 1905 (Vaz, 1905). A infância abandonada é um extenso trabalho em que Vaz descreve e analisa os serviços de assistência à infância do Brasil, dos Estados Unidos e de alguns países europeus, obra que alçou seu autor a uma posição de destaque no cenário dos debates a respeito da infância no país.

34 Ataulpho de Paiva (1865-1955) nasceu na província do Rio de Janeiro. Magistrado e escritor, bacharelou-se na Faculdade de Direito de São Paulo em 1887. Paiva lutou - por meio da imprensa, da publicação de obras e da participação em congressos 
E com razão pondera, ainda, que é preciso não esquecer que essa instituição já não basta por si só, necessitando que se criem outras congêneres, para dar vazão à grande massa de crianças desprotegidas de uma cidade cheia de analfabetos, onde o ensino e a educação são muito descurados, onde a massa ignorante é muito densa e que conta um milhão de habitantes.

Quadro social e demografia são mobilizados como argumentos em defesa da expansão da malha de assistência aos desclassificados. Defesa que reconhece a insuficiência da ação do Estado na defesa da sociedade, ao mesmo tempo em que reforça a tese do perigo representada pela educação descurada e densidade da ignorância. Como se pode ver, ainda que sob um novo regime ou até em virtude disso, assistimos a essa espécie de reemprego do discurso do medo - fórmula muito antiga para se assegurar o recurso à força e legitimação de determinadas formas de governo, como a que se pratica pela via da educação formal.

Como se pode notar, a população aparece como um problema. A demografia como argumento parece cumprir a função de indicar densidades da população em geral, realçando a existência de subpopulações, de outros estratos, com características próprias: a massa de ignorantes e de crianças desprotegidas. ${ }^{35}$ Ao mesmo tempo, o jurista e homem de letras sinaliza para a rarefação das instituições dedicadas a essa subpopulação. Articulado nos polos da ausência e do excesso, Ataulpho de Paiva constrói ou reforça a necessidade de se pensar políticas gerais para esse corpo múltiplo,localizável,numerável que é a população - ou suas frações - da Capital da República.

Para gerir essa multiplicidade, o jurista reclama por mais escola e mais educação, convertendo tais equipamentos em tecnologias a serviço do governo dos outros, mas também em uma espécie de governo de si ou autogoverno. Duplo efeito, cujo alcance decorreria do cruzamento entre fundamentos jurídicos e fundamentos outros que orientavam (ou procuravam orientar) os estabelecimentos construídos para modelar a criança pobre, para controlar os riscos e as virtualidades da "perigosa" população de pequenos. Nesse projeto, saberes forjados na medicina, higiene e pediatria parecem ter sido constituídos nas bases da pedagogia da prevenção, uma espécie de racionalidade renovada para lidar e manter no horizonte um velho problema e formas atualizadas de enfrentar.

nacionais e internacionais - pela sistematização da assistência pública e privada no país, sob a inspeção do Estado. Coordenou, sob encomenda da prefeitura do Rio de Janeiro, um levantamento da assistência pública e privada do município, trabalho publicado em 1922 que reúne dados de cerca de quinhentas instituições assistenciais da capital federal (Sobrinho, 1940).

35 Para observar o tratamento dispensado à subpopulação descrita como perigosa e indesejável, ver Rago (2008). 


\section{CONSIDERAÇÕES FINAIS}

Entre as últimas décadas do século XIX e início do XX, os documentos produzidos pelo poder público para administrar e gerir a população articulavam discursos e políticas distintas que visavam afirmar a necessidade de higienizar e sanear, vacinar, construir habitações salubres, jardins e praças, criar escolas primárias e profissionais, reformar hospitais, hospícios e as instituições penitenciárias.

Os dirigentes lidavam com o que consideravam uma realidade assustadora: crescimento demográfico e população formada por indivíduos de lugares sociais e culturas heterogêneas e plurais. A maioria da população era negra, livre e liberta (ex-escravos) ao final do Império (Censo demográfico de 1872) e, até as três primeiras décadas do período republicano, a cidade do Rio de Janeiro recebeu um grande contingente de imigrantes, principalmente portugueses e italianos (Schueler; Rizzini, 2007). Em meio a essa população que dominava as ruas, pequenos trabalhadores se faziam presentes, vivenciando experiências e exercendo diversas funções na luta cotidiana pela sobrevivência. Moleques de recado, vendedores ambulantes, engraxates, caixeiros do comércio, operários das fábricas de cerveja, de charuto, de sabão e de velas, e das primeiras manufaturas têxteis, criados domésticos e aprendizes de variados ofícios, as crianças trabalhavam em diversas atividades urbanas (Lobo, 1990).

Os discursos sobre a disciplina, a educação e o cuidado com as infâncias emergiram nesse período com significativa visibilidade, compondo uma espécie de tecido discursivo que procurava articular saberes médico-higiênicos, jurídicos, pedagógicos, da assistência social, filantropia e dos sistemas jurídico-policiais. Essa massa de discurso passou a reclamar medidas enérgicas para a disciplina e educação das crianças classificadas como vadias, vagabundas, culpadas, viciosas, delinquentes/ criminosas, órfãs, abandonadas e desvalidas. Trata-se de uma teia discursiva, cujos efeitos se fazem sentir no processo histórico de atualização de representações que demarcam uma clivagem entre os chamados menores (sujeitos que a qualquer momento podem ser submetidos a dispositivos de controle da polícia e da justiça) e as crianças (sujeitos submetidos aos registros da prevenção por meio das políticas educacionais e/ou assistenciais).

Atravessada por discursos e práticas que relacionavam a tecnologia penal e correcional aos dispositivos de educação, reforma e assistência, produzindo representações distintas a respeito do objeto de intervenção, a infância pobre emergiu como problema social a ser enfrentado. Ancorado em racionalidades complementares, o processo de classificação e quadriculamento, ao constituir uma tipologia da infância, colaborou para organizar medidas disciplinares dirigidas à infância desvalida e infeliz, viciosa ou culposa (Brasil, 1879, p. 49).

No campo da medicina e da higiene, como vimos, verifica-se a proliferação discursiva sobre os cuidados e a educação das infâncias - trabalhadora, asilada, desvalida, órfã, maltratada por familiares ou tutores e que vaga pelas ruas -, disseminada por intermédio de meios, tais como, periódicos médicos especializados, revistas para o 
público leigo, teses de doutoramento, artigos em jornais de grande circulação, congressos de proteção e assistência à infância e palestras para grupos sociais distintos, como sociedades acadêmicas, damas de caridade e mães pobres. Mas é sobretudo na passagem do século XIX para o século XX que os médicos higienistas associam à produção intelectual um rol expressivo de intervenções sobre as infâncias e suas famílias. A fundação de instituições de assistência, como os Institutos de Proteção e Assistência à Infância, ${ }^{36}$ a atuação na inspeção higiênica das escolas públicas e a ocupação de cargos nos asilos e institutos para os filhos dos pobres fizeram parte do universo médico de algumas cidades brasileiras no período aqui analisado.

A urbanização e o adensamento das cidades parecem ter recolocado as preocupações com a população pobre na agenda política. Identificada, descrita, mapeada, conhecida, quantificada, localizada, essa população precisava ser gerida. Como tentamos demonstrar ao longo deste estudo, medidas de caráter preventivo são assumidas e acomodadas nesse projeto de gestão da pobreza. Prevenção que implicava recolher, profissionalizar e instruir a infância pobre, submetendo-a a uma experiência de formação higiênica que, prevenindo, visava imprimir utilidade e rentabilidade à vida dos pequenos representantes dos males que ameaçavam a cidade capital, do Império e dos anos iniciais da República.

\section{REFERÊNCIAS}

Arıès, Philippe. História social da criança e da família. 2. ed. Rio de Janeiro: Guanabara, 1981. Bakкer, Nelleke. Child guidance and mental health in the Netherlands. Paedagogica Historica, Reino Unido: Routledge, v. 42, n. 6, p. 769-791, dec. 2006.

Becchi, Egle; Julia, Dominique (Orgs.). Histoire de l'enfance en occident. de l'antiquité au XVII siècle. Paris: Seuil, 1998.v. 2.

Brasil. Relatório do Chefe de Polícia da Corte do ano de 1877.In: Relatório do anno de 1877 apresentado a Assembléa Geral Legislativa na primeira sessão da décima sétima legislatura pelo Ministro e Secretario de Estado dos Negócios da Justiça Conselheiro Lafayette Rodrigues Pereira. Rio de Janeiro: Typografia Perseverança, 1878. Disponível em: <http://brazil.crl.edu/bsd/ bsd/u1871/000568.html>. Acesso em: 11 mar. 2013.

36 Em março de 1899, o médico higienista Moncorvo Filho criou o Instituto de Proteção e Assistência à Infância no Rio de Janeiro com a finalidade de organizar campanhas e ações de educação e assistência à infância. A partir de 1920, a entidade foi transferida para um novo edifício, construído num terreno de oito mil metros quadrados, doado pelo município. Até o ano de 1921, existiam dezessete agremiações desse gênero espalhadas pelo país, criadas com a orientação do médico (Freitas; Kuhlmann Júnior, 2002; Moncorvo Filho, 1926; Wadsworth, 1999). 
. Ministério da Justiça. Congresso Internacional de Stockolmo em 1878. Delegado André Augusto de Pádua Fleury. In: Relatório do anno de 1878 apresentado á Assembléa Geral Legislativa na segunda sessão da décima sétima legislatura pelo Ministro e Secretario de Estado dos Negócios da Justiça Conselheiro Lafayette Rodrigues Pereira. Rio de Janeiro: Typografia Perseverança, 1879. Disponível em: <http://brazil.crl.edu/bsd/bsd/u1872/000247.html>. Acesso em: 11 mar. 2013.

- Ministério do Império. Relatório apresentado á Assembléa Geral Legislativa na segunda sessão da décima oitava legislatura pelo Ministro e Secretario de Estado dos Negócios do Império Rodolpho Epihanio de Souza Dantas. Rio de Janeiro: Typografia Nacional, 1882. Disponível em: <http://brazil.crl.edu/bsd/bsd/u1748/000009.html>. Acesso em: 11 mar. 2013.

. Ministério dos Negócios do Interior. Decreto n. 439, de 31 de maio de 1890. Estabelece as bases para a organização da assistencia à infância desvalida.Disponível em: <http://www2.camara.leg.br/legin/fed/decret/1824-1899/decreto-439-31-maio-1890503049-publicacaooriginal-1-pe.html>. Acesso em: 27 jun 2014.

- Ministério da Justiça e Negócios Interiores. Decreto n. 4.780, de 2 de março de 1903. Aprova o regulamento para a Escola Correcional "Quinze de Novembro". 1903. Disponível em: <http://www6.senado.gov.br/legislacao/ListaTextoIntegral. action?id=47895\&norma=63668>. Acesso em: 11 mar. 2013.

Chauvin, Danièle (Org.). L’imaginaire des âges de la vie. Grenoble: Ellug, 1996.

Costa, Jurandir Freire. Ordem médica e norma familiar. 3. ed. Rio de Janeiro: Graal, 1989.

Coutınho, Afrânio; SousA, José Galante de. Enciclopédia de literatura brasileira. São Paulo: Fundação Biblioteca Nacional; Ministério da Educação e Cultura; Academia Brasileira de Letras; Global, 2001.

Crespo, Jorge. A história do corpo. Rio de Janeiro: Bertrand Brasil, 1990.

Ferreira, Antonio Gomes; Gondra, José Gonçalves. Idades da vida, infância e a racionalidade médico-higiênica em Portugal e no Brasil (séculos XVII-XIX). In: Fernandes, Rogério; Lopes, Alberto; Faria Filho, Luciano Mendes de (Orgs.). Para a compreensão histórica da infância. Porto: Campo das Letras, 2006. p. 153-177.

FonsecA, Alvarenga. Coleção de leis municipais e vetos de 1892-1894. Rio de Janeiro: Typografia do Jornal do Commercio, 1897.

Foucault, Michel. O nascimento da clínica. 4. ed. Rio de Janeiro: Forense Universitária, 1994. . Opoder psiquiátrico. São Paulo: Martins Fontes, 2006.

. Le gouvernement de soi et des autres: cours au Collège de France (1982-1983). Paris: Gallimard/Seuil, 2008.

Freitas, Marcos Cezar de; Kuhlmann Júnior, Moysés (Orgs.). Os intelectuais na história da infância. São Paulo: Cortez, 2002. 
Gondra, José Gonçalves. Artes de civilizar: medicina, higiene e educação escolar na Corte Imperial. Rio de Janeiro: EdUERJ, 2004.

Laplantine, François. Antropologia da doença. São Paulo: Martins Fontes, 1991.

Levi, Giovanni; Schmitt, Jean-Claude. Histoire des jeunes en occident.Paris: Seuil, 1996.v.2.

Lово, Eulália. História do Rio de Janeiro (do capital comercial ao capital industrial e financeiro). Rio de Janeiro: IBMEC, 1990. 2 v.

Machado, Roberto; Loureiro, Angela; Luz, Rogerio; Muricy, Katia. Danação da norma: medicina social e constituição da psiquiatria no Brasil. Rio de Janeiro: Graal, 1978.

Monconvo Filho, Arthur. História da proteção à infância no Brasil (1500-1922). 2. ed. Rio de Janeiro: Editora Paulo Pongetti, 1926.

Moreno Martínez, Pedro. The Hygienist Movement and the modernization of education in Spain. Paedagogica Historica, Reino Unido: Routledge, v. 42, n. 6, p. 793-815, dec. 2006.

- A educação do corpo fora da escola: as origens das colônias de férias na Espanha. Educar, Curitiba: Universidade Federal do Paraná, v. 33, p. 23-37, 2009a.

. De la caridad y la filantropía a la protección social del Estado: las colonias escolares de vacaciones en España (1887-1936). Historia de la Educación: Revista Interuniversitaria, Salamanca: Universidade de Salamanca, n. 28, p. 135-159, 2009 b.

Paiva, Ataulpho de. Justiça e assistência: os novos horizontes. Rio de Janeiro: Typografia do Jornal do Commercio, 1916.

Pereira, Ana Leonor; Pitta, João Rui. Liturgia higienista no século XIX: pistas para um estudo. Revista de História das Ideias, Coimbra: Universidade de Coimbra, v. 15, p. 437-559, 1993.

RAGO, Margareth. Os prazeres da noite: prostituição e códigos de sexualidade feminina em São Paulo (1890-1930). 2. ed. São Paulo: Paz e Terra, 2008.

Rio de Janeiro (Município). Decreto n. 838, de 20 de outubro de 1911. Reforma a lei do ensino primário, normal e profissional e dá outras providências. Rio de Janeiro: Boletins da Prefeitura, p. 21-44, out. 1911.

Rızzını, Irma; SouzA, Maria Zélia Maia de. Uma “casa de educação": o "ensino integral” no Asilo de Meninos Desvalidos (1875-1894). In: Chaves, Miriam; Lopes, Sônia. Instituições educacionais da cidade do Rio de Janeiro: um século de história (1850-1950). Rio de Janeiro: Mauad Editora/FAPERJ, 2009. p. 57-82.

Santos Filho, Lycurgo. História geral da medicina brasileira. São Paulo: Hucitec/Edusp, 1991. v. I e II.

Schwarcz, Lilia Moritz. O espetáculo das raças: cientistas, instituições e a questão racial no Brasil (1870-1930). São Paulo: Companhia das Letras, 1995. 
Schueler, Alessandra; Rizzinı, Irma. A caçada aos menores: disciplina e educação das infâncias nos Relatórios de Justiça e Polícia da Corte Imperial (1860-1889). Revista Educação E Cidadania, Campinas: Átomo, v. 6, n. 1, p. 71-81, 2007.

Sobrinho Velho, João Francisco. Dicionário biobibliográfico. Rio de Janeiro: Ministério da Educação e Saúde, 1940.

SouzA, Maria Zélia Maia de. Educar, trabalhar e civilizar no Asilo de Meninos Desvalidos (1875-1894): caminhos possíveis. Dissertação (Mestrado em Educação) - Universidade Federal do Estado do Rio de Janeiro, Rio de Janeiro, 2008.

Spencer, Herbert. Da educação intellectual, moral e physica. Lisboa: Editora Litteraria Fluminense, 1886.

Universidade Federal do Rio de Janeiro. Catálogo de teses. Rio de Janeiro, 1986.v. I.

Varela, Julia; Alvarez-Uria, Fernando. A maquinaria escolar. Teoria \& Educaşão, Porto Alegre: Pannônica, n. 6, p. 68-96, 1992.

VAZ, Franco. A infância abandonada. Rio de Janeiro: Imprensa Nacional, 1905.

. Nosso rumo. Educação e Pediatria, Rio de Janeiro: Livraria Cruz Coutinho, ano I, n.1, p. 3-21, jun. 1913.

Escola Premunitoria Quinze de Novembro. Relatório apresentado ao Exmo. Sr. Dr. Francisco Valladares, Chefe de Policia do Distrito Federal, pelo Sr. Franco Vaz, director. Exercício de 1913. Rio de Janeiro: Typografia da Escola Premunitoria Quinze de Novembro, 1914.

- O problema da infância abandonada em geral (o que se deve fazer). Trabalho apresentado na Conferência Judiciária-Policial do Rio de Janeiro de 1917. Rio de Janeiro, 1917.

VIANna, Adriana de Resende Barreto. O mal que se adivinha: polícia e menoridade no Rio de Janeiro, 1910-1920. Rio de Janeiro: Arquivo Nacional, 1999.

Vigarello, Georges. O limpo e o sujo: uma história da higiene corporal. São Paulo: Martins Fontes, 1996.

Wadsworth, James E. Moncorvo Filho e o problema da infância: modelos institucionais e ideológicos da assistência à infância no Brasil. Revista Brasileira De História, São Paulo: ANPUH, v. 19, n. 37, set. 1999. Disponível em: <http://www.scielo.br/scielo.php?script=sci_ arttext\&pid=S0102-01881999000100006\&lng=en\&nrm=iso >. Acesso em: 28 abr. 2010.

\section{TESES DA FACULDADE DE MEDICINA DE MONTPELLIER}

BALsAn,Émilien. Sur l’utilité de la gymnastique. Montpellier: Imprimerie Firmin et Cabirou, 1875 .

Blanc, Alphonse-Louis. Considérations medico-philosophiques sur quelques points de l'éducation des enfants. Montpellier: Boehm \& Fils, 1869. 
Caillat, Jules. Essai sur l'hygiene des jeunes gens dans les établissements d'instruction publique. Montpellier: Jean Martel Ainé, 1846.

Chabert, Jean-Louis. Considérations médicales sur la crainte et les effets de cette passion sur l'économie animale. Montpellier: Chez Jean Martel Ainé, 1809.

Champeaux, Palasne. Les côtes du Brésil et de la plata: étude de pathologie et de topographie médicales. Montpellier: Imprimerie Centrale du Midi, 1874.

Evesque, Léon-Paul-Félix. Quelques mots sur l'higiène et l'éducation physique du premier age. Montpellier: Typographie de Pierre Grollier, 1863.

Gachet, Charles-Louis-Emile.Ébauche d'un travail sur l'éducation au point de vue médical. Montpellier: Imprimerie L. Cristin, 1858.

Gourdon, Valentin-Charles-Henri. De l'bygiene publique appliqué à la question de la misère. Montpellier: Imprimerie de L. Cristin, 1847.

HauQuelin, Alfred. Considérations hygiéniques sur les écoles primaires. Montpellier: Imprimerie Centrale du Midi, 1874.

Joyeux, Vital-Louis. Considérations directes et indirectes sur quelques points de l'éducation physique des enfans. Montpellier: De l'imprimerie de la veuve de Jean Martel Ainé, 1798.

Lallemand, Paul-Joseph. Essai sur l'histoire de l'éducation dans l'ancien oratoire en France. Montpellier: 1888.

LaUtaret, Marc-Antoine. Quelques considérations générales sur l'éducation physique des enfans. Montpellier: De l'imprimerie de J. G. Tournel Neveu, 1802.

Paloque, Aimé. De l’éducation physique de la jeunesse. Montpellier: Jean Martel Ané, 1863.

Pereira, Amaro Baptista. Essay sur l'érysipéle chronique que rigne d'une manière endemique a Rio de Janeiro. Montpellier: Chez Jean Martel Ainé, 1809.

Rodrigues, Pierre-Paul. Considérations générales sur la phthisie pulmonaire. Montpellier: Imprimerie de Mme. Vc. Ricard, 1840.

SAvY, A. Pascal. Réflexions sur la gymnastique. Montpellier: Chez Coucourdan, 1808.

Thomas, M. G. Hippolyte. Quelques mots sur l’éducation de la femme. Montpellier: Imprimerie de X. Jullien, 1846.

\section{TESES DA FACULDADE DE MEDICINA DE PARIS}

Biard, Jacques-Auguste. Essai sur l'bygiène des enfans pensionnaires dans les colléges. Paris: De L'imprimerie de Didot Jeune, 1832.

Defert, G. Paul. De l'éducation au point de vue hygiénique. Paris: Rignoux, Imprimeur de la Faculté de Medecine, 1861. 
Droin, A. De l'éducation physique, intellectuelle et morale des jeunes filles. Paris: De L'imprimerie de Didot Jeune, 1836.

Laplace-Chauvac, Joseph-Marie. Dissertation sur quelques points de l'education physique et morale de l'enfant. Paris: De L’imprimerie de Didot le Jeune, 1813.

LACARDONNIÉRE, L. Rosier. Considérations physiologiques sur les dangers de quelques exercices du corps. Paris: De Limprimerie de Didot le Jeune, 1822.

Leriche, Jules-Alphonse. Quelques mots d'higiène appliquée aux maisons d'éducation. Paris: A. Parent, Imprimeur de la Faculté de Medecine, 1864.

Longueville, S. N. P. Langlois. Éducation physique et morale de la jeune fille. Paris: De Limprimerie de Didot le Jeune, 1819.

Plouvier, Édouard-Auguste. Institution et réglement d'un collège sous le point de vue sanitaire. Paris: Imprimerie et Founderie de Rignoux, 1839.

Savaget, Paul. Nécessité d’organiser la médecine publique. Paris: A. Parent, Imprimeur de la Faculté de Medecine, 1883.

Tavares, João Fernandes. Considérations d'hygiène publique et de police médicale applicables a la ville de Rio-Janeiro. Paris: De Limprimerie de Didot le Jeune, 1823.

Vitray, Louis Bouché. Quelques considérations sur l'hygiène dans les maisons d'éducation. Paris: A. Parent, Imprimeur de la Faculté de Medecine, 1874.

Windrif, Édouard-Adolphe. Essai sur l'influence des moyens religieux en médecine. Paris: Imprimerie et Founderie de Rignoux, 1840.

\section{SOBRE OS AUTORES}

Irma Rizzini é doutora em história social pela Universidade Federal do Rio de Janeiro (UFRJ). Professora da mesma instituição.

E-mail: irma.rizzini@gmail.com

José Gonçalves Gondra é doutor em educação pela Universidade de São Paulo (USP). Professor da Universidade do Estado do Rio de Janeiro (UERJ). E-mail: gondra.uerj@gmail.com 